\title{
Metformin is not associated with lactic acidosis in patients with diabetes undergoing coronary artery bypass graft surgery: a case control study
}

Rakan I. Nazer ${ }^{1 *}$ and Khalid A. Alburikan²

\begin{abstract}
Background: Metformin associated lactic acidosis (MALA) is a rare but lethal complication. There is no consensus regarding when to stop and resume metformin in patients who undergo coronary artery bypass grafting (CABG). This study aimed to determine if uninterrupted metformin administration in patients with diabetes undergoing CABG increases the risk of lactic acidosis.

Methods: Over a span of 12 months (2015-2016), 127 patients with type 2 diabetes underwent isolated CABG. Of those, 41 patients (32\%) continued taking metformin and 86 patients (68\%) took other antidiabetic agents. Patients taking metformin took the drug until the day of surgery and resumed taking it $3 \mathrm{~h}$ after extubation.

Results: There were no differences in clinical outcomes or complications between groups. Serial measurement of cardiac, liver, and kidney biomarkers were similar between groups. The mean peak lactic acid level was significantly higher in the non-metformin users (5.4 \pm 2.6 vs. $7.4 \pm 4.1 \mathrm{mmol} / / ; P=0.001)$. Multivariable logistic regression analysis identified the need for vasopressor administration as an independent predictor of lactic acidosis (odds ratio: 7.3, 95\% confidence interval: 2.5-20.6; $P<0.001$ ).

Conclusion: In the absence of risk factors associated with persistent lactic acidosis, such as shock or acute kidney or liver injury, continued peri-operative metformin administration was not associated with the occurrence of lactic acidosis in patients undergoing CABG. Elevated lactic acid levels seem to be directly related to tissue anoxia caused by escalating vasopressor support after surgery.
\end{abstract}

Keywords: Metformin, Coronary artery disease, CABG, Lactic acidosis

\section{Background}

Metformin is an oral antidiabetic agent used as a first line intervention in the treatment of type 2 diabetes. Belonging to the biguanide group of hypoglycemics, metformin mainly acts by suppressing gluconeogenesis in the liver, decreasing glucose absorption in the digestive tract, and increasing muscle and fatty tissue sensitivity to insulin [1]. Metformin associated lactic acidosis (MALA) is a rare but fatal condition with a reported incidence of

\footnotetext{
* Correspondence: raknazer@ksu.edu.sa

${ }^{1}$ Department of Cardiac Science, King Fahad Cardiac Center, College of Medicine, King Saud University, KSU 3642, Riyadh 12372-7143, Kingdom of Saudi Arabia

Full list of author information is available at the end of the article
}

3.3-9.7 cases per 100000 patient-years and a mortality rate of up to $45 \%[2,3]$. The accumulation of lactate is in part due to the inhibition of the respiratory chain in the mitochondrial membrane, leading to decreased uptake of pyruvate, which acts as a precursor to lactate in gluconeogenesis [4]. Independent from its glucose lowering effect, metformin monotherapy has been linked to weight reduction, improved survival, reduction of myocardial infarction size, reduced risk of infection, and a significant reduction in overall cardiovascular morbidity [5-9]. Currently, there are no existing safety guidelines concerning metformin administration during the perioperative period in patients scheduled for surgery. Some suggest discontinuing metformin therapy $48 \mathrm{~h}$ prior to surgery $[10,11]$. Others see 
no reason to discontinue its use unless other major risks for lactic acidosis co-exist, such as renal failure, liver failure, respiratory failure, and shock $[7,12]$.

The objective of this study was to determine whether continuing perioperative metformin administration in patients with diabetes during coronary artery bypass grafting (CABG) leads to significant lactate accumulation when compared to patients with diabetes who are not treated with metformin.

\section{Methods}

This study was approved by our institutional research ethics committee and conformed to the tenets of the Declaration of Helsinki, and the electronic registry for all cardiac procedures performed at King Fahad Cardiac Center was interrogated for isolated on-pump CABG from the beginning of December 2014 up to the beginning of January 2016 (12 months). One month prior to this interval, we adopted the policy of continued administration of metformin up to the day of surgery and its early resumption soon after extubation (within 2-3 h) in patients with diabetes who were originally on this drug, in the absence of contraindications or other risk factors for lactic acidosis. Contraindications to metformin therapy were defined as follows: renal dysfunction (creatinine clearance less than or equal to $60 \mathrm{ml} / \mathrm{min}$ ) and receiving two or more nephrotoxic medications. A total of 193 patients undergoing isolated on-pump CABG were identified. Of those, 127 patients (65\%) had type 2 diabetes mellitus. In this subset, 41 patients $(32 \%)$ were on long-term metformin therapy (mean duration, $26 \pm$ 9 months). The remaining 86 patients (68\%) were on other hypoglycemic agents. Home insulin was used by 24 patients (20\%); of those, 6 patients (5\%) used insulin combined with metformin. The other 18 patients (14\%) on insulin therapy used either insulin alone or combined with other non-metformin antidiabetic agents. Patients who used metformin were labeled as group I and those who did not use metformin were labeled as group II. Individual patient consent was waived and all relevant demographic, clinical, and laboratory data were retrospectively collected from the patients' charts, intensive care unit (ICU) flow sheets, and electronic laboratory records. Serum lactic acid was measured on an hourly basis in the ICU during blood gases analysis, and the peak lactic acid (mmol/L) within the first $24 \mathrm{~h}$ after surgery was recorded for every patient in the study. Similarly, the lowest bicarbonate $\left(\mathrm{HCO}_{3}\right)(\mathrm{mmol} / \mathrm{L})$ and peak carbon dioxide $\left(\mathrm{PCO}_{2}\right)(\mathrm{mmHg})$ were recorded from blood gas analysis in the first $24 \mathrm{~h}$ after surgery. Cardiac enzymes total creatinine kinase [total CK (U/L)], creatinine kinase $\mathrm{MB}$ fraction [CK-MB (U/L)], and troponin I (ug/L) were measured daily for first two days after surgery, and the peak level of each enzyme was recorded for every patient in the study. Fasting blood glucose $(\mathrm{mmol} / \mathrm{L})$, serum creatinine (umol/L), total bilirubin $(\mathrm{mmol} / \mathrm{L})$, alkaline phosphatase (ALP) (U/L), alanine aminotransferase (ALT) (U/L), aspirate aminotransferase (AST) (U/L), gamma-glutamyltransferase (GGT) (U/L), and lactate dehydrogenase $(\mathrm{LDH})(\mathrm{U} / \mathrm{L})$ were measured prior to surgery and daily for up to 7 days after surgery. Post-operative fasting glucose was recorded as the mean level after surgery and the peak level of the remaining enzymes was recorded for each patient after surgery. Acute kidney injury after surgery was defined as a greater than $50 \%$ increase in baseline serum creatinine. Post-operative lactic acidosis was defined as an elevation of serum lactate to $5 \mathrm{mmol} / \mathrm{l}$ or greater with a bicarbonate level less than $22 \mathrm{mmol} / \mathrm{l}$ on blood gas analysis [13].

All patients underwent CABG under general anesthesia with full heparinization and central cannulation of the aorta and right atrium. The heart was arrested with cold blood potassium cardioplegia. All patients received a left internal mammary graft on the left anterior descending coronary artery with a segment of the greater saphenous vein on the other coronary targets. Intraoperatively, blood glucose was measured every $30 \mathrm{~min}$ along with activated clotting time (ACT), electrolytes, and blood gases. Once the patient arrived in the ICU, blood glucose was measured every hour. All patients were subjected to a hospital-wide standardized glycemic control protocol using continuous regular insulin infusion. The aim of therapy was to maintain blood glucose between 5.6$8.3 \mathrm{mmol} / \mathrm{l}$ in the operating room and ICU. If blood glucose exceeded $13.8 \mathrm{mmol} / \mathrm{l}$, then added boluses of regular insulin were administered in accordance with a sliding scale. When blood glucose reached $3.3-5.5 \mathrm{mmol} / \mathrm{l}$, insulin infusion was reduced by $50 \%$. When blood glucose was $<3.3 \mathrm{mmol} / \mathrm{l}$, insulin infusion was stopped and $50 \mathrm{ml}$ of $50 \%$ dextrose bolus was administered. After surgery, all patients spent at least $24 \mathrm{~h}$ in the ICU; thereafter they were transferred to a monitored bed in the cardiac ward until the day of discharge. Patients on metformin prior to surgery received the following dosages: $500 \mathrm{mg}$ (72\%), $850 \mathrm{mg}(20 \%)$, and 1,000 $\mathrm{mg}(8 \%)$ every $12 \mathrm{~h}$.

Statistical analysis was performed using SPSS 16.0 software (SPSS Inc., Chicago, IL). Categorical data were tabulated in $2 \times \mathrm{n}$ tables and two-group comparisons were performed using the chi-square test or Fisher exact test. Continuous variables were expressed as means \pm standard deviations. The $\mathrm{t}$ test was used to compare twogroup continuous variables. Variables deemed important by univariable analysis $(P<0.2)$ or those deemed clinically significant were entered into a multivariable logistic regression model. The results are expressed as odds ratios (OR), 95\% confidence interval (95\% CI), and $P$ values. A two-tailed value of $<0.05$ was considered to be significant for all statistical tests. 


\section{Results}

For both groups (group I: metformin users, group II: other hypoglycemic users), demographic characteristics including age, sex, body mass index (BMI), history of acute myocardial infarction, ventricular function, and symptoms were similar. The calculated operative mortality risks according to European System for Cardiac Operative Risk Evaluation (EURO II ) for the two groups were statistically similar (group I: $1.08 \pm 0.1$, group II: $1.29 \pm 0.1, P=0.257$; Table 1). Glycosylated hemoglobin A1C \% (HbA1C) was significantly higher in group I (9.0 \pm 1.5 vs. $8.1 \pm 1.6 ; P=0.010)$. Perioperatively, there were no significant differences in the cardiopulmonary bypass or cross-clamp times $(103.5 \pm 32.3$ vs. $100.8 \pm 38.9 \mathrm{~min}$, $P=0.709$ and $83.2 \pm 31.3$ vs. $79.8 \pm 32.3, \quad P=0.590$, respectively; Table 2). The peak blood glucose values recorded intraoperatively were significantly higher for group I $(11.5 \pm 2.6$ vs. $10.4 \pm 3.1 \mathrm{mmol} / \mathrm{L} ; P=0.034)$. The immediate postoperative course was similar for both groups. The mean cardiac index in group I and group II was $3.0 \pm 0.5$ vs. $2.9 \pm 0.5 \mathrm{~L} / \mathrm{M}^{2} / \min (P=0.277)$ and the time spent on the ventilator was $8.0 \pm 15.0$ vs. $8.0 \pm 9.2 \mathrm{~h}$ $(P=0.998)$, respectively. When comparing the postoperative laboratory measurements (Table 3), fasting blood glucose was significantly higher in group I (10.0 \pm 1.3 vs. $8.9 \pm 2.1 \mathrm{mmol} / \mathrm{l} ; P=0.001)$. Interestingly, the need for more than one vasopressor in the immediate postoperative period was significantly higher in group II (12.2\% vs. $27.9 \% ; P=0.049)$. There were no significant differences in the peak levels of cardiac enzymes, creatinine, and liver enzymes (Table 3). Other clinical outcomes revealed a trend for lower rates of myocardial infarction, atrial fibrillation, low output state, and surgical site infection in group I, but these differences did not reach statistical significance. Two patients died perioperatively ( $0 \%$ in group I vs. $2.3 \%$ in group II; $P=1.0$ );

Table 1 Baseline characteristics

\begin{tabular}{|c|c|c|c|}
\hline & Group I Diabetes + metformin $n=41$ (32\%) & Group II Diabetes - metformin $n=86(68 \%)$ & $P$-value \\
\hline Age (years) $\pm S D$ & $57.3 \pm 9.2$ & $57.2 \pm 10.0$ & 0.969 \\
\hline Female (\%) & $7(17.1 \%)$ & $11(12.8 \%)$ & 0.518 \\
\hline Body mass index (BMI) & $27.6 \pm 5.2$ & $27.8 \pm 5.6$ & 0.832 \\
\hline Myocardial infarction (STEMI/NSTEMI) & $19(46.3 \%)$ & $51(59.3 \%)$ & 0.170 \\
\hline Urgent CABG & $6(14.6 \%)$ & $18(20.9 \%)$ & 0.397 \\
\hline Post-op stay (days) $\pm \mathrm{SD}$ & $7.3 \pm 7.2$ & $8.7 \pm 19.6$ & 0.658 \\
\hline Median post-op stay (days) & 5.0 & 5.0 & \\
\hline New York Heart Association Class III-IV (\%) & $12(29.3 \%)$ & $21(24.4 \%)$ & 0.560 \\
\hline Canadian Cardiac Society Class III-IV (\%) & $28(68.3 \%)$ & $44(51.2 \%)$ & 0.069 \\
\hline Ejection fraction <40 (\%) & $9(22.0 \%)$ & $14(16.3 \%)$ & 0.438 \\
\hline EuroSCORE II & $1.08 \pm 0.1$ & $1.29 \pm 0.1$ & 0.257 \\
\hline Redo-CABG & 0 & 0 & \\
\hline \multicolumn{4}{|l|}{ Risk factors and comorbidities } \\
\hline Insulin injection (\%) & $6(14.6 \%)$ & $18(20.9 \%)$ & 0.397 \\
\hline Glycosylated Hemoglobin A1C (\%) & $9.0 \pm 1.5$ & $8.1 \pm 1.6$ & 0.010 \\
\hline Total cholesterol-HDL ratio & $4.8 \pm 2.9$ & $5.0 \pm 1.7$ & 0.729 \\
\hline Baseline serum creatinine (umol/l) & $87.0 \pm 22.0$ & $93.0 \pm 22.8$ & 0.165 \\
\hline Blood sugar (mmol/l) & $11.0 \pm 4.3$ & $10.8 \pm 18.9$ & 0.950 \\
\hline Hypertension (\%) & $36(87.8 \%)$ & $68(79.1 \%)$ & 0.232 \\
\hline Hyperlipidemia (\%) & $27(65.9 \%)$ & $45(52.3 \%)$ & 0.150 \\
\hline Positive family history (\%) & $8(19.5 \%)$ & 18 (20.9\%) & 0.853 \\
\hline Current smoking (\%) & $7(17.1 \%)$ & $23(26.7 \%)$ & 0.230 \\
\hline Chronic lung disease (\%) & $0(0 \%)$ & $6(7.0 \%)$ & 0.176 \\
\hline Stroke (\%) & $3(7.3 \%)$ & $5(5.8 \%)$ & 0.712 \\
\hline Peripheral vascular disease (\%) & $1(2.4 \%)$ & $11(12.8 \%)$ & 0.101 \\
\hline Elevated creatinine $>140 \mathrm{umol} / \mathrm{l}(\%)$ & $1(2.4 \%)$ & $5(5.8 \%)$ & 0.663 \\
\hline Significant carotid disease (\%) & $0(0 \%)$ & $4(4.7 \%)$ & 0.304 \\
\hline Viral hepatitis (\%) & $1(2.4 \%)$ & $1(1.2 \%)$ & 0.543 \\
\hline
\end{tabular}


Table 2 Peri-operative outcomes

\begin{tabular}{llll}
\hline & Group I Diabetes + Metformin $n=41$ (32\%) & Group II Diabetes - Metformin $n=86$ (68\%) & $P$-value \\
\hline Ventilation time (hours) \pm SD & $8.0 \pm 15.0$ & $8.0 \pm 9.2$ & 0.998 \\
Intensive care time (hours) \pm SD & $42.8 \pm 33.7$ & $46.1 \pm 45.4$ & $100.8 \pm 38.9$ \\
Cardiopulmonary bypass time (minutes) \pm SD & $103.5 \pm 32.3$ & $79.8 \pm 32.3$ & 0.692 \\
Cross clamp time (minutes) \pm SD & $83.2 \pm 31.3$ & $2.9 \pm 0.5$ & 0.709 \\
Post-op cardiac index (mean) \pm SD & $3.0 \pm 0.5$ & $55.9 \pm 8.6$ & $24(27.9 \%)$ \\
Lowest mixed venous oxygen saturation \% (SVO2) & $55.8 \pm 6.4$ & $8(9.3 \%)$ & 0.590 \\
Number of vasopressors $>1$ & $5(12.2 \%)$ & $6(7.0 \%)$ & 0.277 \\
Intra-aortic balloon pump (\%) & $2(4.9 \%)$ & $21(24.4 \%)$ & $1(1.2 \%)$ \\
Myocardial infarction (\%) & $1(2.4 \%)$ & $7(8.1 \%)$ & 0.950 \\
Low output syndrome (\%) & $7(17.1 \%)$ & $19(22.1 \%)$ \\
New post-op dialysis (\%) & $0(0 \%)$ & $3(3.5 \%)$ & 0.4989 \\
Atrial Fibrillation (\%) & $0(0 \%)$ & $7(8.1 \%)$ & 0.351 \\
Pulmonary complications (\%) & $7(17.1 \%)$ & $2(2.3 \%)$ & 1.000 \\
Stroke/Transient ischemic attack (\%) & $1(2.4 \%)$ & & 0.095 \\
Surgical site infection (\%) & $2(4.9 \%)$ & $0(0 \%)$ & 1.000 \\
Death (\%) & & 0.717 \\
\hline
\end{tabular}

Table 3 Peri- operative laboratory measurements

\begin{tabular}{|c|c|c|c|}
\hline & Group I DM + Meformin $n=41$ (32\%) & Group II DM - Metformin $n=86(68 \%)$ & $P$-value \\
\hline \multicolumn{4}{|l|}{ Serum glucose } \\
\hline${ }^{\text {a}}$ Fasting blood sugar $(\mathrm{mmol} / \mathrm{l}) \pm \mathrm{SD}$ & $10.0 \pm 1.3$ & $8.9 \pm 2.1$ & 0.001 \\
\hline \multicolumn{4}{|l|}{ Cardiac enzymes } \\
\hline${ }^{b}$ Peak CK $(U / I) \pm S D$ & $1128.5 \pm 1065.1$ & $1062.6 \pm 772.8$ & 0.693 \\
\hline${ }^{b}$ Peak CK-MB $(U / I) \pm S D$ & $86.4 \pm 126.9$ & $82.3 \pm 66.9$ & 0.809 \\
\hline 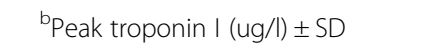 & $2.1 \pm 3.1$ & $3.3 \pm 4.8$ & 0.185 \\
\hline \multicolumn{4}{|l|}{ Kidney } \\
\hline${ }^{\mathrm{b}}$ Peak creatinine $(\mathrm{mmol} / \mathrm{l}) \pm \mathrm{SD}$ & $109.7 \pm 25.9$ & $119.8 \pm 37.2$ & 0.122 \\
\hline 'Acute kidney injury & $7(17.1 \%)$ & $17(19.8 \%)$ & 0.717 \\
\hline \multicolumn{4}{|l|}{ Liver } \\
\hline${ }^{b}$ Peak total bilirubin $(\mathrm{mmol} / \mathrm{l}) \pm \mathrm{SD}$ & $17.6 \pm 15.5$ & $21.1 \pm 15.7$ & 0.244 \\
\hline${ }^{b}$ Peak $A L P(U / I) \pm S D$ & $119.7 \pm 57.9$ & $135.9 \pm 92.7$ & 0.307 \\
\hline bPeak ALT $(U / I) \pm S D$ & $71.0 \pm 85.1$ & $124.6 \pm 251.3$ & 0.079 \\
\hline${ }^{b}$ Peak AST $(U / I) \pm S D$ & $88.0 \pm 108.1$ & $134.7 \pm 278.6$ & 0.303 \\
\hline${ }^{b}$ Peak GGT $(U / I) \pm S D$ & $99.0 \pm 90.8$ & $107.9 \pm 120.7$ & 0.677 \\
\hline \multicolumn{4}{|l|}{ Other laboratory measures } \\
\hline${ }^{b}$ Peak LDH $(U / I) \pm S D$ & $414.0 \pm 159.8$ & $543.7 \pm 337.2$ & 0.021 \\
\hline${ }^{b}$ Peak lactic acid $(\mathrm{mmol} / \mathrm{l}) \pm \mathrm{SD}$ & $5.4 \pm 2.6$ & $7.4 \pm 4.1$ & 0.001 \\
\hline Mean lactic acid $(\mathrm{mmol} / \mathrm{l}) \pm \mathrm{SD}$ & $3.1 \pm 3.2$ & $5.7 \pm 4.4$ & 0.001 \\
\hline${ }^{\mathrm{d}}$ Transient lactic acidosis (\%) & $15(23.8 \%)$ & $48(76.2 \%)$ & 0.043 \\
\hline${ }^{b}$ Peak PCO2 $\left.(\mathrm{mmHg})\right) \pm \mathrm{SD}$ & $41.3 \pm 3.5$ & $40.4 \pm 4.5$ & 0.235 \\
\hline eLowest $\mathrm{HCO} 3(\mathrm{mmol} / \mathrm{l}) \pm \mathrm{SD}$ & $20.1 \pm 1.8$ & $18.9 \pm 2.8$ & 0.008 \\
\hline
\end{tabular}

${ }^{a}$ The mean post-operative fasting blood glucose

${ }^{b}$ The mean of the highest reading in the peri-operative period \pm standard deviation

${ }^{c}$ Elevation of serum creatinine $>50 \%$ of baseline measurement

${ }^{\mathrm{d}}$ The patients with transient post-operative lactic acid $>5 \mathrm{U} / \mathrm{l}$ and bicarbonate $<22 \mathrm{mmol} / \mathrm{l}$

' $T$ The mean of the lowest reading in the peri-operative period \pm standard deviation 
deaths were due to perioperative myocardial infarction and post-cardiotomy shock. The mean peak lactic acid level (Table 3) was significantly higher in group II (5.4 \pm 2.6 vs. $7.4 \pm 4.1 \mathrm{mmol} / \mathrm{l} ; P=0.001$; Fig. 1 ) as was the mean post-operative lactic acid in the first $24 \mathrm{~h}$ after surgery $(3.1 \pm 3.2$ vs. $5.7 \pm 4.4 \mathrm{mmol} / \mathrm{l} ; P=0.001$; Fig. 2$)$. Lactic acid levels peaked for both groups within the first $2 \mathrm{~h}$ after surgery, and thereafter reduced to baseline 8-10 h after surgery (around the time of extubation). There was no difference between the two groups in perioperative peak $\mathrm{PCO}_{2}(41.3 \pm 3.5$ vs. $40.4 \pm 4.5 \mathrm{mmHg} ; P=0.235)$. Peak LDH was also higher in group II (414.0 \pm 159.8 vs. $543.7 \pm$ $337.2 \mathrm{U} / \mathrm{l} ; P=0.021$ ). There were also more patients in group II who developed transient post-operative lactic acidosis (arterial lactate level $>$ or $=5 \mathrm{mmol} / \mathrm{L}$ and serum bicarbonate of $<$ or $=22 \mathrm{mmol} / \mathrm{l})(23.8 \%$ vs. $76.2 \%$, $P=0.043)$. A multivariable logistic regression model was used to evaluate the following factors: age $>70$ years, elevated post-operative creatinine $>50 \%$ of baseline, cardiac low output state, continued perioperative metformin, and the requirement for vasopressors in the ICU. This analysis revealed that additional vasopressor use was an independent predictor for transient post-operative lactic acidosis (OR: 7.26, 95\% CI: $2.55-20.65 ; P<0.0001$ ) within the first $24 \mathrm{~h}$ after CABG (Table 4).

\section{Discussion}

Combining metformin with insulin in non-cardiac surgical ICU patients is associated with better glucose control without the occurrence of lactic acidosis [14-16]. The intention of this study was to determine the incidence of adverse events related to the early administration of metformin after CABG. As with earlier studies, our investigation did not indicate that metformin was associated with a significant increase in lactic acid levels when compared to patients who were not taking metformin for diabetes. In fact, in a systemic review by Salpeter et al. [4] evaluating pooled data from 347 comparative trials comparing the incidence of lactic acidosis in patients with diabetes who took metformin versus those who did not, a lower incidence of lactic acidosis was found in the metformin group $(0.0043 \%$ vs. $0.0054 \%)$. However, no cardiac surgery patients were included in this analysis. A similar finding was reported by Stang et al. [17] Similarly, our cohort study shows a smaller peak in serum lactate in patients who used metformin early after CABG $(5.4 \pm 2.6$ vs. $7.4 \pm 4.1 ; P=0.001)$, which was associated with a significantly higher bicarbonate level $(20.1 \pm 1.8$ vs. $18.9 \pm 2.8 ; P=0.008)$. The occurrence of lactic acidosis with metformin ingestion is rare and sporadic [18]. The majority of patients who developed lactic acidosis usually have other serious underlying conditions such as shock, sepsis, or acute kidney or liver disease. In both animal and human models, hypothermic cardio-pulmonary bypass was associated with subtle hemodynamic changes in the mucosal and hepatic sinusoidal microcirculations, which add to splanchnic hypoperfusion and ischemia [19]. This is further aggravated by the post-operative increased oxygen demand, low output cardiac state, and use of

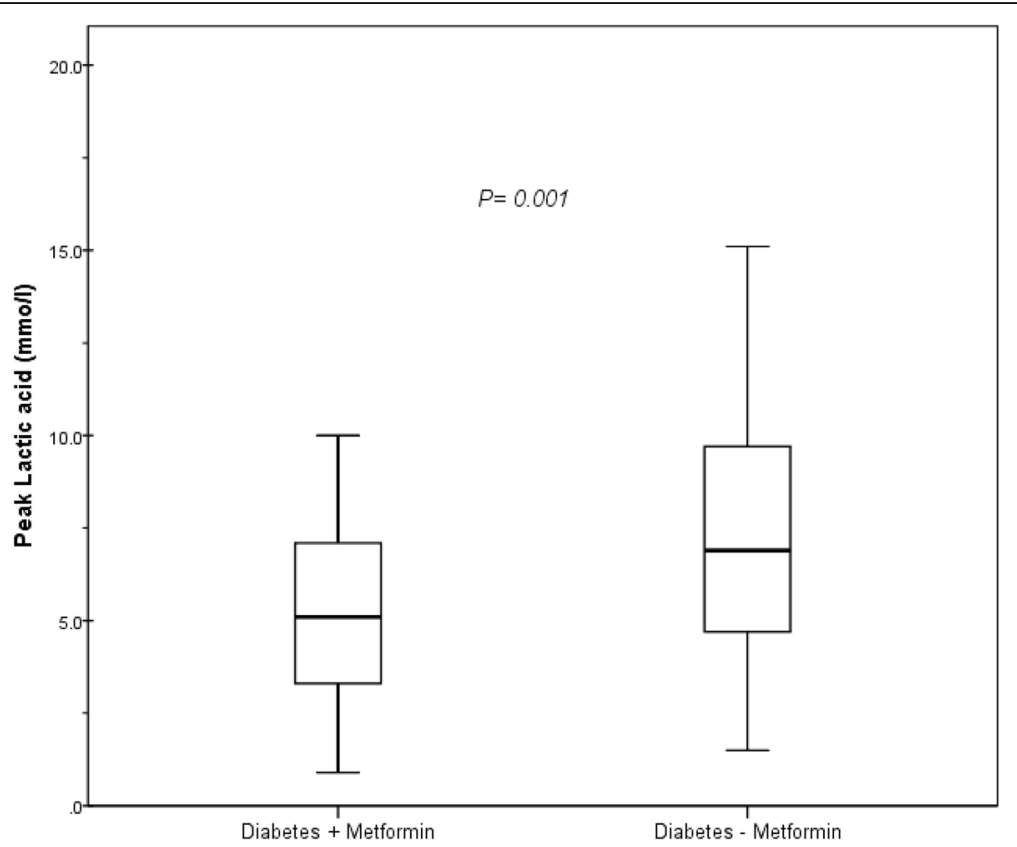

Fig. 1 Comparison of peak serum lactic acid levels in the first $24 \mathrm{~h}$ after surgery in the two patient groups. (Patients with diabetes who took metformin perioperatively = Diabetes + metformin, patients with diabetes were not on metformin = Diabetes - metformin) 


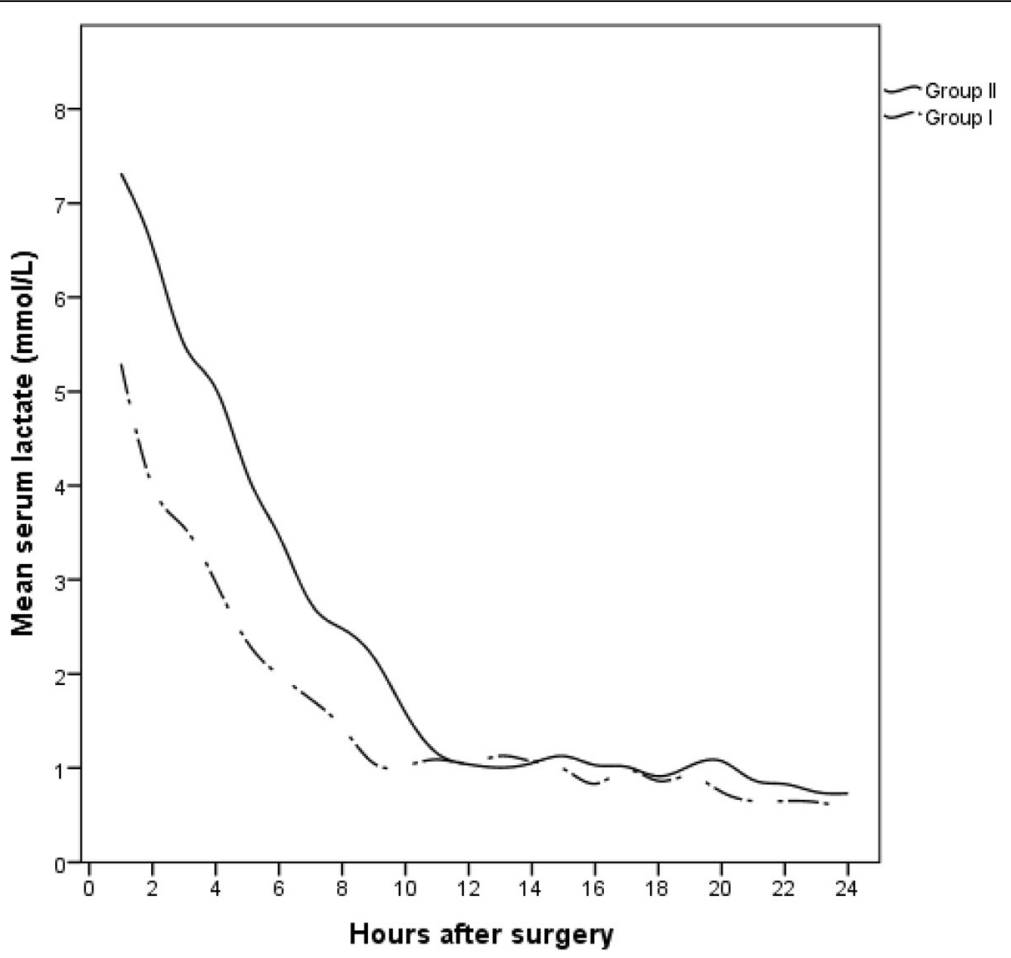

Fig. 2 Linear trend of the mean lactic acid levels in the first $24 \mathrm{~h}$ after surgery (Patients with diabetes who took metformin perioperatively= Group I, patients with diabetes who were not on metformin = Group II)

vasoactive agents. This cascade of events can inflect visceral organ injury manifesting in a recognized pattern of liver, kidney, and pancreas biomarker surge within the first 2-3 days after surgery [20-22].

Metformin use in patients with diabetes undergoing cardiac surgery was not shown to increase the risk for adverse cardiac outcomes. Duncan et al. [7] retrospectively matched 443 patients who took metformin up to $8 \mathrm{~h}$ prior to cardiac surgery with the same number of non-metformin treated patients using propensity scores. There was no difference in major adverse events between the two groups. In fact, the metformin users had overall less morbidities (OR (95\% CI) 0.4 (0.2-0.8); $P=0.005)$, leading the authors to suggest that pretreatment with metformin might have beneficial effects. In a randomized clinical trial, Baradari et al. [23] randomized 200 patients with diabetes to either high dose metformin $(1,000 \mathrm{mg})$ twice daily versus placebo within
$3 \mathrm{~h}$ of extubation after CABG. There were no differences in the serum lactate levels during the 5 consecutive days after surgery and there was no acidosis in either group. Another prospective study done by the same group found that adding metformin to insulin regimens led to better glycemic control in patients with diabetes who undergo CABG without causing metabolic acidosis [24]. It is not clear in both of these studies whether metformin was continued up until the day of surgery or stopped a few days prior. El Messaoudi et al. [25] randomized 111 patients without diabetes to $500 \mathrm{mg}$ metformin three times a day versus placebo 3 days prior to elective on-pump CABG. Similarly, there was no increase in lactic acidosis or adverse events in the metformin group. In the current study, all patients in group I received metformin up until the day of surgery and resumed taking it $2-3 \mathrm{~h}$ post extubation. We observed a trend towards more peri-operative myocardial infarction,

Table 4 Logistic regression predictors for peri-operative lactic acidosis

\begin{tabular}{lll}
\hline Variables & Univariable analysis & Multivariable analysis \\
\hline Age $>70$ & OR: $1.53 ; 95 \% C l ~ 0.75-3.12, P=0.237$ & OR: $2.12 ; 95 \% C l 0.93-4.83, P=0.073$ \\
Elevated serum creatinine $>50 \%$ & OR: $1.01 ; 95 \% C l 0.19-5.2, P=0.984$ & OR: $1.69 ; 95 \% C l 0.23-12.30, P=0.601$ \\
Peri-operative metformin & OR: $0.45 ; 95 \% C l ~ 0.21-0.98, P=0.045$ & OR: $1.78 ; 95 \% C l 0.77-4.09, P=0.174$ \\
Cardiac low out-put state & OR: $2.16 ; 95 \% C l 0.91-5.15, P=0.082$ & OR: $1.74 ; 95 \% C l 0.49-6.17, P=0.393$ \\
Vassopressor support & OR: $7.26 ; 95 \% C l ~ 2.55-20.65, P<0.0001$ & OR: $11.77 ; 95 \% C l 2.86-48.37, P<0.001$ \\
\hline
\end{tabular}


atrial fibrillation, and infection in group II, which might explain the need for additional vasopressors in the ICU. Epinephrine and other vasoconstrictive agents may cause vasoconstriction and elevation in serum lactate following cardiopulmonary bypass. In a study by Jabbari et al. [26], 15 patients had their lactic acid level measured in the operating room and ICU. The average lactate was initially $0.83 \pm 0.28 \mathrm{mmol} / \mathrm{l}$ on induction for surgery, $0.87 \pm 0.33$ a half hour from induction, $2.84 \pm$ 1.68 after a quarter of an hour on cardio-pulmonary bypass, $3.48 \pm 2.23$ at the end of cardio-pulmonary bypass, $4.28 \pm 2.48$ at the end of surgery, and $4.33 \pm 2.56$ during ICU admission. A similar study by Meng et al. [22] measured lactate and other inflammatory markers in patients undergoing on-pump CABG every $6 \mathrm{~h}$ for $24 \mathrm{~h}$ after the start of cardio-pulmonary bypass. The lactate was recorded as follows: T0 $(1.12 \pm 1 \mathrm{mmol} / \mathrm{l})$, T1 (1.15 \pm 0.07$), \mathrm{T} 2(3.12 \pm 0.21), \mathrm{T} 3(2.97 \pm 0.18), \mathrm{T} 4$ $(2.58 \pm 0.25)$. Our current study has identified the use of vasopressors in the peri-operative period as an independent predictor of lactic acidosis. Other authors have identified increased lactate concentration after on-pump CABG to be associated with total inotrope dosage, hemodynamic parameters, duration of pump time, and cross-clamp time [26].

The current study is limited by its retrospective nature, its small sample size, and variability in metformin dosage; however, it confirms the same findings reported in other studies [18, 23, 24, 26, 27].

\section{Conclusion}

Our results show that continuing metformin administration in the peri-operative period is unlikely to cause lactic acidosis or other major adverse events. Evidence from the literature indicates that metformin use in patients with diabetes after CABG surgery tends to be associated with better glucose control and reduced complications.

\section{Abbreviations \\ 95\% Cl: 95\% confidence interval; ACT: Activated clotting time; ALP: Alkaline phosphatase; ALT: Alanine aminotransferase; AST: Aspirate aminotransferase; BMI: Body mass index; CABG: Coronary artery bypass grafting; Euro ॥ score: European System for Cardiac Operative Risk Evaluation Score; GGT: Gamma- glutamyltransferase; HbA1C: Glycosylated hemoglobin A1C \%; HCO3: Bicarbonate; ICU: Intensive care unit; LDH: Lactate dehydrogenase; MALA: Metformin associated lactic acidosis; OR: Odds ratios; PCO2: Peak carbon dioxide}

\section{Acknowledgements}

This project was supported by College of Medicine Research Centre, Deanship of Scientific Research, King Saud University.

\section{Funding}

No funding was required for this study.

\section{Availability of data and materials}

The datasets used and/or analyzed during the current study are available from the corresponding author on reasonable request.

\section{Authors' contributions}

RIN designed the study, collected the data, and wrote the manuscript. KMA performed the analysis and was involved in drafting the manuscript. Both authors read and approved the final manuscript.

\section{Competing interests}

The authors declare that they have no competing interests.

\section{Consent for publication}

Not applicable.

\section{Ethics approval and consent to participate}

This study was approved by King Saud University College of Medicine Institutional Review Board No. E-13-1041. As this was a retrospective study with no direct patient identifiers revealed, individual consent was waived.

\section{Publisher's Note}

Springer Nature remains neutral with regard to jurisdictional claims in published maps and institutional affiliations.

\section{Author details}

${ }^{1}$ Department of Cardiac Science, King Fahad Cardiac Center, College of Medicine, King Saud University, KSU 3642, Riyadh 12372-7143, Kingdom of Saudi Arabia. ${ }^{2}$ Department of Clinical Pharmacy, College of Pharmacy, King Saud University, Riyadh, Kingdom of Saudi Arabia.

Received: 23 December 2016 Accepted: 16 May 2017

Published online: 30 May 2017

\section{References}

1. Sirvinskas E, Kinduris S, Kapturauskas J, Samalavicius R. Perioperative use of metformin in cardiac surgery. Medicina (Kaunas). 2010;46(11):723-9.

2. Lalau JD. Lactic acidosis induced by metformin: incidence, management and prevention. Drug Saf. 2010;33(9):727-40.

3. Lalau JD, Race JM. Lactic acidosis in metformin-treated patients. Prognostic value of arterial lactate levels and plasma metformin concentrations. Drug Saf. 1999;20(4):377-84.

4. Salpeter SR, Greyber E, Pasternak GA, Salpeter EE. Risk of fatal and nonfatal lactic acidosis with metformin use in type 2 diabetes mellitus. Cochrane Database Syst Rev. 2010;4:CD002967.

5. El Messaoudi S, Rongen GA, de Boer RA, Riksen NP. The cardioprotective effects of metformin. Curr Opin Lipidol. 2011;22(6):445-53.

6. Effect of intensive blood-glucose control with metformin on complications in overweight patients with type 2 diabetes (UKPDS 34). UK Prospective Diabetes Study (UKPDS) Group. Lancet. 1998;352(9131):854-65.

7. Duncan Al, Koch CG, Xu M, Manlapaz M, Batdorf B, Pitas G, Starr N. Recent metformin ingestion does not increase in-hospital morbidity or mortality after cardiac surgery. Anesth Analg. 2007;104(1):42-50.

8. Jorgensen $\mathrm{CH}$, Gislason $\mathrm{GH}$, Andersson $\mathrm{C}$, Ahlehoff $\mathrm{O}$, Charlot M, Schramm TK, Vaag A, Abildstrom SZ, Torp-Pedersen C, Hansen PR. Effects of oral glucose-lowering drugs on long term outcomes in patients with diabetes mellitus following myocardial infarction not treated with emergent percutaneous coronary intervention - a retrospective nationwide cohort study. Cardiovasc Diabetol. 2010;9:54

9. Lexis $C P$, Wieringa WG, Hiemstra B, van Deursen VM, Lipsic E, van der Harst $P$, van Veldhuisen DJ, van der Horst IC. Chronic Metformin treatment is associated with reduced myocardial infarct size in diabetic patients with ST-segment elevation myocardial infarction. Cardiovasc Drugs Ther. 2013. https://www.ncbi.nlm.nih.gov/pubmed/24292206.

10. Mercker SK, Maier C, Neumann G, Wulf H. Lactic acidosis as a serious perioperative complication of antidiabetic biguanide medication with metformin. Anesthesiology. 1997;87(4):1003-5.

11. Maznyczka A, Myat A, Gershlick A. Discontinuation of metformin in the setting of coronary angiography: clinical uncertainty amongst physicians reflecting a poor evidence base. Eurolntervention. 2012;7(9):1103-10.

12. Lustik SJ, Vogt A, Chhibber AK. Postoperative lactic acidosis in patients receiving metformin. Anesthesiology. 1998:89(1):266-7. author reply 267-8.

13. Luft D, Deichsel G, Schmulling RM, Stein W, Eggstein M. Definition of clinically relevant lactic acidosis in patients with internal diseases. Am J Clin Pathol. 1983;80(4):484-9. 
14. Mojtahedzadeh M, Jafarieh A, Najafi A, Khajavi MR, Khalili N. Comparison of metformin and insulin in the control of hyperglycaemia in non-diabetic critically ill patients. Endokrynol Pol. 2012;63(3):206-11.

15. Panahi Y, Mojtahedzadeh M, Zekeri N, Beiraghdar F, Khajavi MR, Ahmadi A Metformin treatment in hyperglycemic critically ill patients: another challenge on the control of adverse outcomes. Iran J Pharm Res. 2011;10(4):913-9.

16. Ansari G, Mojtahedzadeh M, Kajbaf F, Najafi A, Khajavi MR, Khalili H, Rouini MR, Ahmadi H, Abdollahi M. How does blood glucose control with metformin influence intensive insulin protocols? Evidence for involvement of oxidative stress and inflammatory cytokines. Adv Ther. 2008;25(7):681-02.

17. Stang M, Wysowski DK, Butler-Jones D. Incidence of lactic acidosis in metformin users. Diabetes Care. 1999;22(6):925-7.

18. Lalau JD, Race JM. Lactic acidosis in metformin therapy: searching for a link with metformin in reports of 'metformin-associated lactic acidosis'. Diabetes Obes Metab. 2001;3(3):195-201.

19. Hessel 2nd EA. Abdominal organ injury after cardiac surgery. Semin Cardiothorac Vasc Anesth. 2004;8(3):243-63.

20. Shahbazi S, Panah A, Sahmeddini MA. Evaluation of factors influencing liver function test in on-pump coronary artery bypass graft surgery. Iran J Med Sci. 2013;38(4):308-13.

21. Yamada T, Ochiai R, Takeda J, Kikuchi H, Ishibashi M, Watanabe K. Off-pump coronary artery bypass attenuates transient hepatocellular damage after myocardial revascularization. J Cardiothorac Vasc Anesth. 2005;19(5):603-7.

22. Meng QH, Zhu S, Sohn N, Mycyk T, Shaw SA, Dalshaug G, Krahn J. Release of cardiac biochemical and inflammatory markers in patients on cardiopulmonary bypass undergoing coronary artery bypass grafting. J Card Surg. 2008;23(6):681-7.

23. Baradari AG, Habibi MR, Khezri HD, Aarabi M, Khademloo M, Jalali Z, Ghafari R. Does high-dose metformin cause lactic acidosis in type 2 diabetic patients after CABG surgery? A double blind randomized clinical trial. Heart Int. 2011;6(1):e8.

24. Baradari AG, Emami Zeydi A, Aarabi M, Ghafari R. Metformin as an adjunct to insulin for glycemic control in patients with type 2 diabetes after CABG surgery: a randomized double blind clinical trial. Pak J Biol Sci. 2011;14(23):1047-54.

25. El Messaoudi S, Nederlof R, Zuurbier CJ, van Swieten HA, Pickkers P, Noyez L, Dieker H-J, Coenen MJ, Donders ART, Vos A, et al. Effect of metformin pretreatment on myocardial injury during coronary artery bypass surgery in patients without diabetes (MetCAB): a double-blind, randomised controlled trial. Lancet Diab Endocrinol. 2015:3(8):615-23.

26. Jabbari ABN, Alijanpour E, Vafaey HR, Alereza H, Rabiee SM. Serum lactate as a prognostic factor in coronary artery bypass graft operation by on pump method. Caspian J Inter Med. 2013:4(2):66266.

27. Totaro RJ, Raper RF. Epinephrine-induced lactic acidosis following cardiopulmonary bypass. Crit Care Med. 1997;25(10):1693-9.

\section{Submit your next manuscript to BioMed Central and we will help you at every step:}

- We accept pre-submission inquiries

- Our selector tool helps you to find the most relevant journal

- We provide round the clock customer support

- Convenient online submission

- Thorough peer review

- Inclusion in PubMed and all major indexing services

- Maximum visibility for your research

Submit your manuscript at www.biomedcentral.com/submit 